\title{
Catalogo del fondo Stendhal. Biblioteca Primoli, a cura di Massimo Colesanti, I; a cura di Massimo Colesanti e Valeria Petitto, II
}

\section{Michel Arrous}

\section{(2) OpenEdition Journals \\ Édition électronique \\ URL : http://journals.openedition.org/studifrancesi/9586 \\ DOI : 10.4000/studifrancesi.9586 \\ ISSN : 2421-5856 \\ Éditeur \\ Rosenberg \& Sellier}

\section{Édition imprimée}

Date de publication : 1 décembre 2007

Pagination : 674-675

ISSN : 0039-2944

\section{Référence électronique}

Michel Arrous, « Catalogo del fondo Stendhal. Biblioteca Primoli, a cura di Massimo Colesanti, l; a cura di Massimo Colesanti e Valeria Petitto, II », Studi Francesi [En ligne], 153 (LI | III) | 2007, mis en ligne le 30 novembre 2015, consulté le 12 janvier 2021. URL : http://journals.openedition.org/studifrancesi/9586 ; DOI : https://doi.org/10.4000/studifrancesi.9586

Ce document a été généré automatiquement le 12 janvier 2021.

\section{cc) (1) $\odot$}

Studi Francesi è distribuita con Licenza Creative Commons Attribuzione - Non commerciale - Non opere derivate 4.0 Internazionale. 


\title{
Catalogo del fondo Stendhal. Biblioteca Primoli, a cura di Massimo Colesanti, I; a cura di Massimo Colesanti e Valeria Petitto, II
}

\author{
Michel Arrous
}

\section{RÉFÉRENCE}

Catalogo del fondo Stendhal. Biblioteca Primoli, a cura di Massimo colesAnTI, I; a cura di Massimo COLESANTI e Valeria PETITTO, II, «Quaderni di cultura francese», n. 35 e n. 39, Roma, Edizioni di Storia e Letteratura, 2002 e 2006, pp. 358 e 563.

1 La longue tâche est achevée: grâce aux travaux de Massimo Colesanti et Valeria Petitto, nous disposons désormais du répertoire complet du fonds Stendhal de la Bibliothèque Primoli, soit les livres, essentiellement des fonds Primoli et Mario Praz, qui ont appartenu à Stendhal ou le concernent de près ou de loin, avec la bibliographie des traductions italiennes, des études spécialisées et des recueils d'actes.

Certains de ces livres ont appartenu à des napoléonides (la princesse de Canino, Caroline Murat, le roi Joseph). C'est en quelque sorte la recension des livres que Stendhal a connus, lus, annotés, utilisés, cités ou qu'il a pu lire, voire qu'il n'a sans doute jamais lus. À l'identification complète de l'ouvrage s'ajoutent, le cas échéant, un renvoi au fonds Bucci, la mention d'ouvrages postérieurs à 1842, ainsi que d'utiles compléments sur les enrichissements du fonds moderne.

Dans le tome I, on lira avec profit la transcription améliorée des notes que Stendhal a laissées sur ses œuvres, Rome, Naples et Florence en 1817 (relue en 1830, 1831, 1839), la Vie de Rossini (relue en 1823-1824, 1826, 1835, 1838, 1839), ou sur celles de Duclos, Miccichè, Napoléon-Marchand, ou encore sur La Jacquerie (relue en 1832). À ce propos, la lecture de la note de la p. 64: «Je reste sec comme de l'âme à clore [?; à don(ner)?]» me paraît 
devoir être corrigée: «Je reste sec comme de l'amadou». Dans la section «Lettres, manuscrits et documents», t. II, M. Colesanti et V. Petitto donnent une lecture améliorée de la lettre de Stendhal à D. Bucci du 25 février 1842 (Correspondance générale, t. VI, p. 573), la liste des correspondants français du comte Primoli qui se sont plus ou moins intéressés à Stendhal (Barrès, Blum, Bourget, France, Lemaître, etc...) et, entre autres documents, une copie manuscrite du $H B$, brochure dont le comte Primoli dit qu'elle a été flétrie par Pelletan «comme elle le méritait». Un index complète ce second volume.

4 Le catalogue du fonds Primoli constitue un utile supplément aux catalogues des fonds Bucci, à Milan, et Stendhal, à Grenoble. 